\title{
Relaciones entre el empleo, calidad de vida y gran empresa en la producción para exportación de espárragos en el Perú: El caso de los valles de La Libertad e Ica
}

\author{
Johans Julio E. V. López Mas ${ }^{1}$ \\ Pablo M. Condori Luna ${ }^{2}$
}

\section{RESUMEN}

El propósito es observar las dinámicas económicas y poblacionales a partir de la comparación entre la producción y exportación de espárragos en dos valles de la costa peruana: Ica en el sur y Virú en el norte del Perú. Este es un ejemplo ilustrativo de la manera como la costa peruana se incorpora a la lógica y dinamica del sistema alimentario fresco a escala mundial y asume con el espárrago una posicion de liderazgo en el mercado internacional.

Los niveles tecnológicos y productividades en los dos valles mencionados son diferentes (en varios factores, por ejemplo en la productividad por hectárea) así como las distancias hacia los centros de acopio y de exportación; sin embargo, percibimos la tendencia empresarial de liderazgo de complejos agroindustriales modernos, que combinan la creación de ventajas basadas en la investigacion y desarrollo

1 Doctor en Historia de las Economías y Sociedades, EHESS, París. Profesor Principal y Director del Instituto de Investigaciones de la Facultad de Ciencias Administrativas de la UNMSM. E-mail: johans_jlopez@ yahoo.com

2 Licenciado en Administración de la UNMSM. E-mail: pcondoril@gmail.com 


\title{
Johans Julio E. V. López Mas / Pablo M. Condori Luna
}

tecnológico, la diversificacion de cultivos y mercados destino, y la mantención de la explotación de mano de obra barata.

Palabras clave: Dinámicas económicas - productivas, cluster, espárragos, precarizacion del empleo, actividad agroexportadora.

\begin{abstract}
The purpose is to note the economic and population dynamics from the comparison between asparagus production and exports in two valleys of peruvian coast: Ica in southern Peru and Viru and northern Peru. This is an example of how peruvian coast is incorporated into the logic and dynamic of the global fresh food system and it assumes with asparagus a leadership position in the international market.

Technological and producivity levels in the two valleys mentioned are different (in many factors, such as in productivity per hectare) as well as distances to collection and export centers; nevertheless, we perceive the leadership corporate tendency in complex agroindustrial modern corporates, combining the creation of R\&D-based advantages, diversificating crops, targeting markets, and maintaining cheap labor cost exploitation.
\end{abstract}

Keywords: Dynamic economic-productive, asparagus cluster, precarious employment, agricultural export activity.

\section{INTRODUCCIÓN}

La investigación que a continuación se presenta busca describir y explicar la existencia de diferencias en los resultados en términos de producción y distribución de la riqueza, además de los demás impactos que involucran la actividad agroindustrial. Hemos observado que entre dos localidades que se dedican a la agricultura de exportación de espárragos existen diferencias de orden tecnológico y de productividad, así como desigualdades socioeconómicas e impactos territoriales diferenciados. Un ejemplo de ello son los valles en Ica y de Virú en La Libertad.

Ademas, se indaga las tendencias de precarización del empleo agroindustrial, además de los ingresos, debido a una politica empresarial de costos que asigna al trabajo 


\section{El caso de los valles de La Libertad e Ica}

una contribución menor en el valor del producto, a pesar del uso intensivo de mano de obra abundante proveniente de regiones aledañas (Ayacucho y Cajamarca, respectivamente); mientras que busca la eficiencia en la mejora tecnológica y las normas de aseguramiento de calidad, sobre la base de las condiciones climaticas excepcionales que posee el país.

La investigación se ha propuesto como objetivos los siguientes:

- Analizar la dinámica económico - productiva y social en las zonas de exportación de espárragos, con énfasis en la composición, calidad del empleo y los ingresos de la población.

- Especificar el impacto del empleo y los ingresos de los productores y asalariados en las regiones dedicadas a las actividades de agroexportación de espárragos así como la dinámica empresarial de los integrantes de la cadena de producción que soporta la actividad agroexportadora.

La hipótesis de investigación propuesta señala que la precarización de la fuerza laboral y de las poblaciones que se encuentran en la zona de explotación de la producción esparraguera, es un componente característico de esta actividad, y se manifiesta en: 1) La mantención de la agricultura de contrata, subordinada a la explotación de las grandes empresas que están integradas al mercado internacional; 2) la existencia de un bajo poder de negociación en las relaciones entre el empresario y el trabajador, por la abundancia de mano de obra de la zonas aledañas a las regiones involucradas; además de las relaciones desiguales entre agricultor, acopiador e industriales, en la conformación de precios y en la toma de posiciones de riesgo; 3) la consolidacion de grandes complejos agroindustriales que lideran las exportaciones de esparragos y otros productos alimentarios naturales.

\section{PRINCIPALES RESULTADOS}

\section{a. Producción de espárragos en el Perú}

El cultivo del espárrago se inició en el Perú a principios de la década del 50, en el departamento de La Libertad, con la variedad Mary Washington, destinándose la tota- 


\section{Johans Julio E. V. López Mas / Pablo M. Condori Luna}

lidad de la producción a conservas de espárrago blanco. Pero es a partir de los años 80 cuando el espárrago presenta un notable crecimiento, impulsado por la iniciativa de la Asociación de Productores de Ica, que en 1986 inició un Programa de Producción de Espárrago Verde, para su exportación en fresco, basado en la variedad UC 157/F1 con uso de tecnología californiana. Este proyecto contó con apoyo de la AID, que facilitó la realización del estudio en el país y la visita de dos expertos peruanos a las zonas productoras de espárrago en Estados Unidos.

Hasta entonces, prácticamente, toda la producción estaba localizada en los valles de Moche, Virú y Chao, destinada totalmente a conservas y ocupando un área, aproximadamente, de $8000 \mathrm{Ha}$. La acertada difusión del cultivo basada en los altos rendimientos que sobrepasaron los valores estimados, logró un crecimiento acelerado en muy pocos años. Con el ingreso del valle de Ica a la exportación de espárrago fresco se generó un gran crecimiento que duplicó el área en solo una década, polarizándose la producción entre el Norte tradicional, representado por el departamento de La Libertad y áreas menores en departamentos vecinos, que continuó produciendo espárrago blanco; y el Sur Medio, que cubriendo los valles de Chincha y Cañete, principalmente, se dedicó al espárrago verde fresco, generando en su crecimiento, la industria del congelado para el espárrago de menor calidad y la cosecha de otoño, que por coincidencia con la del hemisferio norte, no podía exportarse como fresco. Posteriormente, la realizacion de la irrigación de Chavimochic en los valles de la costa de La Libertad, ha permitido la incorporación de nuevas hectáreas para la agricultura, especialmente de espárrago.

Actualmente, los valles de La Libertad, ubicados en el norte, y los de Ica, en la zona sur, son las dos principales zonas de producción de espárragos en el Perú. Ambas, tienen condiciones naturales privilegiadas que combinadas con la tecnología y cualidades empresariales, han convertido al Perú en el más grande exportador de espárrago del mundo (en sus tres presentaciones).

En el 2008, la situacion de los valles de la Libertad, dedicados al esparrago, era la siguente: $15014.88 \mathrm{Ha}$ instaladas (11 237 Ha, Virú; 2340.18 Ha, Trujillo; $1278.20 \mathrm{Ha}$, Ascope; 153 Ha, Chepén; y 6 Ha, Pacasmayo).

En el censo de productores y procesadoras de espárragos del año 1998 aparecen los siguientes datos (Cuadro $\mathrm{N}^{\circ} 1$ ) de la producción y el rendimiento del espárrago; ade- 


\section{El caso de los valles de La Libertad e Ica}

más de la forma en cómo ha ido evolucionando la producción hasta el 2004 (Cuadro N. ${ }^{\circ}$ ):

Cuadro N. ${ }^{\circ}$ 1. Producción anual de los principales cultivos.

\begin{tabular}{lccc}
\hline Departamento & Producción (Tm) & Rendimiento Kg x Ha & Superficie Cultivada \\
\hline Áncash & 5620 & 4543 & 1237 \\
Arequipa & 328 & 6560 & 50 \\
Ica & 77141 & 9329 & 8269 \\
La Libertad & 63455 & 7774 & 8262 \\
Lambayeque & 896 & 3829 & 234 \\
Lima & 19753 & 7017 & 2815 \\
Piura & 1163 & 5359 & 217 \\
\hline
\end{tabular}

Fuente: Censo de productores y procesadoras de espárrago (1998). MINAG

Cuadro N. ${ }^{\circ}$ 2. Perú, producción de espárragos de los cuatro principales departamentos 19912004 (miles tm)

\begin{tabular}{|c|c|c|c|c|c|c|c|c|c|c|c|c|c|c|}
\hline & 1991 & 199 & 199 & 199 & 199 & 1996 & 1997 & 1998 & 1999 & 200 & 2001 & 2002 & 200 & 2004 \\
\hline La Libertad & 48 & 53 & 60 & 73 & 44 & 54 & 52 & 60 & 61 & 54 & 84 & 84 & 92 & 96 \\
\hline Ica & 7 & 8 & 19 & 35 & 3 & 45 & 57 & 52 & 85 & 65 & 76 & 77 & 76 & 76 \\
\hline Lima & 3 & 5 & 7 & 10 & 9 & 14 & 13 & 16 & 20 & 17 & 17 & 14 & 14 & 13 \\
\hline Áncash & 0 & 2 & 2 & 2 & 1 & 3 & 7 & 6 & 5 & 6 & 4 & 4 & 4 & 6 \\
\hline Perú & 65 & 74 & 97 & 131 & 108 & 128 & 145 & 138 & 175 & 143 & 184 & 181 & 187 & 190 \\
\hline $\begin{array}{l}\text { Superficie } \\
\text { Cosechada } \\
\text { (miles de Ha) }\end{array}$ & 11 & 13 & 18 & 18 & 20 & 23 & 17 & 16 & 19 & 15 & 19 & 19 & 19 & 19 \\
\hline
\end{tabular}

Fuente: MINAG Ministerio de Agricultura. 2008. Elaboración: Inform@cción

En la actualidad, existe en el Perú un cluster del espárrago, que incluye al Instituto Peruano del Espárrago y Hortalizas (IPEH), gremio representativo de la industria, y a la Asociación Civil Frío Aéreo, que cuenta con un centro de perecibles con modernas cámaras de frío en el aeropuerto internacional de Callao Jorge Chávez, a través de las cuales se despacha el $80 \%$ del espárrago fresco exportado. En el Perú, se ubican también, la empresa congeladora de espárragos y la planta empacadora más grandes del mundo y toda la industria pertenece a capitales nacionales.

La Norma Técnica Peruana para el Espárrago Fresco (2.12.2008), la tercera que se publica en diez años, fue desarrollada de forma conjunta por el Estado y productores privados. 


\section{Johans Julio E. V. López Mas / Pablo M. Condori Luna}

La regulación establece los calibres, tolerancias, presentación, contaminantes e higiene que deben cumplir los espárragos peruanos para su comercialización.

\section{b. Salarios obreros en la producción esparraguera}

La investigacion realizada nos señala que a pesar de tratarse de un mismo cultivo de espárragos, existen importantes diferencias en las características de producción entre el valle de Virú - Chao y el valle de Ica, pero tienen algunos aspectos comunes; por ejemplo, el $75 \%$ de los productores son pequeños ( $<5 \mathrm{Ha}$ ); $28 \%$, medianos ( 5.1 a $15 \mathrm{Ha}$ ); y solo el $1 \%$, superiores a 15 Has. Los pequeños productores no están organizados y venden la materia prima en forma individual a los acopiadores que la recogen diariamente.

En el caso de los trabajadores, su contratacion está regida por la Ley de Régimen Laboral Agrario 27360, (31.10.00) que contiene características especiales:

a) Tienen derecho a percibir una remuneración diaria (RD) no menor a S/. 16.00 (dieciséis y 00/100 nuevos soles), siempre y cuando laboren más de 4 (cuatro) horas diarias en promedio. Dicha remuneración incluye a la compensación por tiempo de servicios y las gratificaciones de fiestas patrias y navidad y se actualiza en el mismo porcentaje que los incrementos de la remuneración mínima vital. (En la actualidad el salario mínimo en el sector esparraguero es de S/. 643.00, es decir, S/. 21.40 nuevos soles/día).

b) El descanso vacacional es de 15 (quince) días calendario remunerados por año de servicio o la fracción que corresponda, salvo acuerdo entre trabajador y empleador para un período mayor.

c) En caso de despido arbitrario, la indemnización es equivalente a 15 (quínce) RD por cada año completo de servicios con un máximo de 180 (ciento ochenta) RD. Las fracciones de años se abonan por dozavos.

Algunas diferencias entre los dos valles estudiados:

- En el caso del espárrago de Virú se destina al mercado internacional de conservas. La actividad tiene un carácter permanente a lo largo del año. En Ica, en cambio, el proce- 


\section{El caso de los valles de La Libertad e Ica}

samiento de espárragos tiene una marcada estacionalidad, pues el $50 \%$ de la producción se destina en fresco al mercado estadounidense en época de contraestación.

- En Trujillo, el espárrago es un cultivo de pequeños productores, con bajo nivel tecnológico, rendimientos reducidos y baja productividad. En Ica, en cambio, el espárrago es cultivado por medianos productores, con tecnologías modernas y altos rendimientos.

- En Trujillo, los productores agrícolas no están integrados verticalmente, negocian individualmente con las empresas procesadoras las condiciones de venta de materia prima. En Ica, en cambio, sí existe un nivel de organización, por ejemplo, a través de la Asociación de Exportadores de Espárrago.

- La rentabilidad del cultivo es otro factor que diferencia a Trujillo de Ica. Si bien el precio internacional del espárrago tiene tendencia a la baja; para los agricultores iqueños, la actividad esparraguera es rentable, por las características tecnológicas y organizativas, los altos niveles de productividad y la integración que han alcanzado. Se puede afirmar que en Ica el espárrago es un cultivo floreciente y en ascenso. En la Libertad, tenemos una situacion compleja, donde encontramos pequeños productores que no encuentran en el cultivo de espárrago una actividad rentable, debido a problemas tecnológicos, bajos rendimientos y falta de organización, así como a grandes empresas situadas en Chavimochic.

- Respecto al grado educativo de la mano de obra, destaca el alto nivel (lo que fue confirmado mediante las entrevistas de campo) en Ica; en cambio, en Trujillo, hay muchos trabajadores con estudios secundarios. Aun cuando hay que diferenciar a los trabajadores de campo, muchos de ellos migrantes provenientes de zonas pobres del país, y los dedicados a actividades industriales, que requieren niveles mayores de calificacion.

Algunas semejanzas en ambas localizaciones productivas:

- La mayor parte de los trabajadores del espárrago son eventuales, ya sea a nivel de campo o de planta procesadora. Estos trabajadores se desempeñan por periodos variables. 


\section{Johans Julio E. V. López Mas / Pablo M. Condori Luna}

- Los niveles salariales en ambos casos son en su mayoría bastante bajos; y según la ley laboral especial dada por Fujimori, se mantiene el recorte de beneficios laborales en comparacion con el conjunto de trabajadores. Con dos agravantes: La agroexportación tiene grandes ganancias y la mayoría de trabajadores son migrantes que viven en condiciones precarias. No existe en su mayoria diferencia con lo que se paga en otros cultivos, aunque es posible distinguir mecanismos para incentivar el rendimiento laboral. Por ejemplo, en el Consorcio Agroindustrial Camposol (Chavinochic, La Libertad) existe un sistema de bonos que varía según el producto y las funciones desempeñadas por el trabajador, tales como: "clasificado", la empresa paga S/. 0.76 por jaba repleta; "pelado", el bono varía en funcion al diámetro del espárrago; "campo", la prima para aquel trabajador que supera los 140 kilos de cosecha al día es S/. 0.32 por kilo extra. Con estos mecanismos, el ingreso neto de un trabajador promedio varía entre S/. 1200.00 y S/. 1400.00 nuevos soles mensuales, según datos proporcionados por la empresa (diciembre de 2008).

- A nivel de campo. Es una norma extendida la jornada de ocho horas, así como el pago monetario. En las fábricas, el esfuerzo de los trabajadores para ser más productivos se convierte en una carta de recomendación para no tratar de ser despedidos cuando los requerimientos de mano de obra disminuyen.

- A nivel de centros de acopio e industrias. La jornada es de ocho horas y media, pues el refrigerio corre a cuenta del trabajador.

- No existen organizaciones laborales a nivel de centros de campo, centros de acopio e industria. Sin embargo, casos especiales, así en 2007, se estableció una primera base sindical en Camposol (Chavimochic), y luego aparecieron otras dos bases sindicales. En 2008, la empresa sufrió su primer paro de 24 horas que paralizó la cosecha con pérdida diaria de 1 millón de dolares. En el departamento de Ica se han constituido los 2 primeros sindicatos que han logrado sobrevivir a las represalias de las empresas. Se trata del "Sindicato de la empresa Agrokasa" y el "Sindicato de Trabajadores de la Compañía de Exportación y Negocios Generales S.A. - COEXA". 


\section{El caso de los valles de La Libertad e Ica}

También se observa, que el espárrago tiene un importante efecto en la generación de empleo (cada hectárea alrededor de 150 jornales por campaña), existen cerca de 50 000 puestos de trabajo en la actividad esparraguera.

Respecto a las relaciones laborales, se informa que, paradójicamente, frente a estos sostenidos crecimientos de la producción agroexportadora y la generación de empleo, persiste una situación recurrente de violación de los derechos laborales, fuertes inequidades sociales y niveles de pobreza muy acentuados. Mientras la economía creció un $28 \%$ en 4 años, el salario real está como en el 2000. Mientras la rentabilidad de las empresas crece, los sueldos de trabajadores/ras permanecen constantes. (el $60 \%$ de la PEA ocupada son mujeres). Hay que destacar que en las plantas de procesamiento de los productos como el espárrago, más del $95 \%$ son mujeres, esto por las "habilidades manuales" mejor desarrolladas que los hombres.

La realidad de Ica y la de la La Libertad no son ajenas a estas desigualdades. En el departamento de Ica, al 2006, la PEA ocupada fue de 95\%, con un nivel de desocupación del $4.3 \%$. Las actividades que realizan los ocupados son aquellas vinculadas a los sectores de servicios y agricultura, los que concentraron al 31,6\% y 29,6\% del total, respectivamente. Si bien estas actividades concentran la mayor cantidad de trabajadores, son actividades que generan bajos ingresos, así la actividad agrícola (en el que se encuentra el sector agro exportador) generó en promedio ingresos mensuales de alrededor de S/. 446 (US\$140), es decir, por debajo de la remuneración mínima legal, S/. 500 (US\$ 158). Para el 2005, el $40 \%$ de las/os trabajadores más pobres accedió a apenas al 10,8\% del ingreso total, en tanto el 10\% más rico accedió al 39,2\% del ingreso laboral regional.

Según informacion oficial del MINAG; en el valle Virú, durante la campaña 2007/2008, la mano de obra era escasa debido mayormente a la fuerte demanda de las empresas esparragueras que absorben mano de obra en las cosechas.

\section{c. Modalidades de articulación interempresarial}

La empresa agro industrial puede optar por tres alternativas distintas para el abastecimiento de su insumo agrícola: primero, comprar en el mercado abierto; segundo, 


\section{Johans Julio E. V. López Mas / Pablo M. Condori Luna}

contratar productores independientes que pueden ser grandes, medianos o pequeños (coordinación vertical o integración horizontal); y tercero, abastecerse por producción propia en sus tierras o en tierras arrendadas (integración vertical); o mediante una combinación de dichas opciones. El gráfico N ${ }^{\circ} 1$ ilustra lo señalado. Fuera de estas alternativas, la opción es salir del mercado, cambiar de rubro -o de región, en el caso de la agroindustria- y dar otros destinos a la tierra y al trabajo en el caso de la pequeña agricultura.

Gráfico N. ${ }^{\circ}$ 1. Formas de articulación empresarial

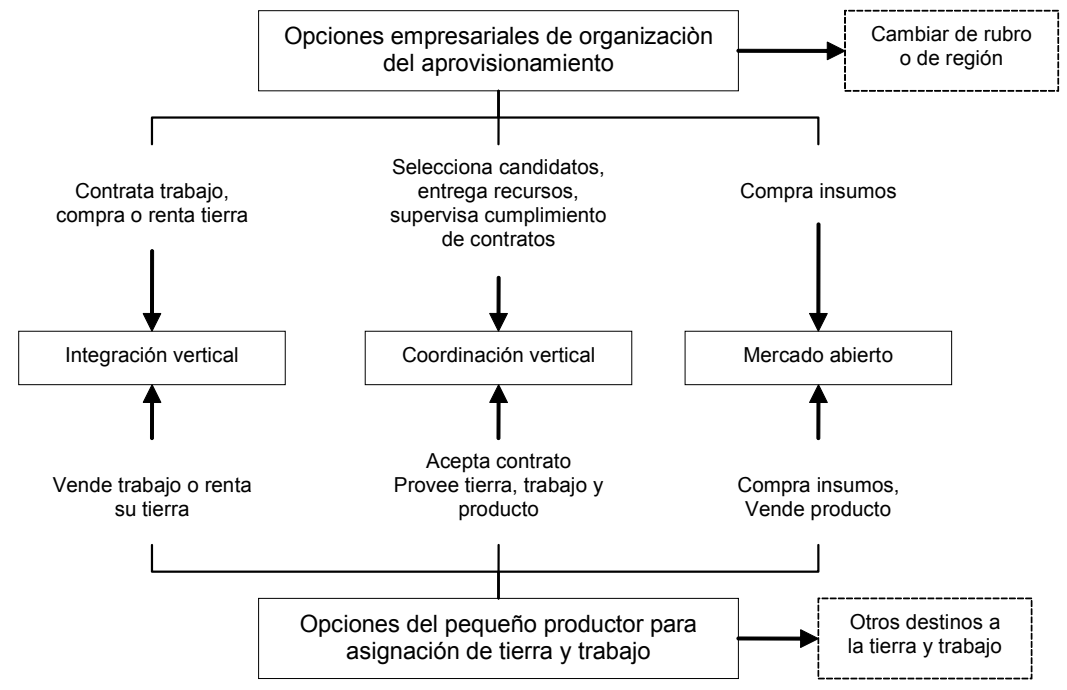

Fuente: Caro, Carlos (2000), p. 125.

El abastecimiento del producto se hace a través del mercado abierto cuando concurren muchos compradores y muchos vendedores anónimos. La agroindustria compra su insumo básico en el mercado, y la pequeña agricultura también vende su producción y se abastece de insumos necesarios en el mercado. No hay ningún tipo de contrato. Esto se da siempre y cuando la necesidad de adaptación del producto sea autónoma; es decir, la agroindustria puede adaptar el insumo a sus necesidades sin que el pequeño productor adapte su producto, o viceversa. 


\section{El caso de los valles de La Libertad $\in$ Ica}

Se usan mecanismos de coordinación vertical si hay transacciones frecuentes en las que la entrega es justo a tiempo, o en transacciones donde predomina la adaptación cooperativa. Esto es lo que se conoce como agricultura de contrata. Aquí la agroindustria selecciona candidatos, entrega recursos y supervisa el cumplimiento de los contratos, mientras que la pequeña agricultura proporciona el producto, su tierra y su trabajo, pues ha aceptado un contrato. El precio pagado por un producto también influye en las relaciones de coordinación vertical, pues cuando hay poca diferenciación de precios en función de la calidad o de la homogeneidad del producto, disminuyen las razones para entrar en una relación de coordinación vertical y más bien aumentan las razones para transar en el mercado abierto.

La integración vertical tiende a ser la norma en los casos de alta especificidad del producto, o cuando existen economías de escala entre la cercanía del lugar de producción del insumo y el lugar de procesamiento, o cuando los costos de producción y los costos de supervisión propia son menores que aquellos en los que habría que incurrir si se optase por la producción de terceros.

Entonces, lo que determinará cualquiera de las tres opciones (mercado abierto, coordinación vertical o integración vertical) depende de varias razones. Para la agroindustria, la determinación de la opción a tomar dependerá de cuál sea la alternativa que asegure calidad, cantidad, regularidad y flexibilidad (para cambiar de rubro) del flujo de insumos, además que la opción tomada sea coherente con su capacidad instalada y con el nivel, composición y dinámica de la demanda de su producto. Entonces, esta optará por la alternativa de menor costo que le permita lograr dichas condiciones. En cambio, para el pequeño agricultor, la determinación de la opción dependerá del nivel de ingreso esperado y de la magnitud de los riesgos involucrados en las distintas alternativas a su alcance.

Esta situación permite una gran flexibilidad y capacidad de negociación para el productor para la agroexportación, el cual puede en simultáneo sembrar y cultivar sus propias extensiones de terrenos, fungir de demandante de producción a otros agricultores de menor escala. 


\section{Johans Julio E. V. López Mas / Pablo M. Condori Luna}

\section{CARACTERÍSTICAS DE LAS EMPRESAS AGROINDUSTRIALES}

Las protagonistas de la rápida expansión de la exportación de espárragos frescos en el Perú a partir de mediados de la década de 1990 son las empresas agrícolas modernas que introducen nuevas tecnologías e integran los procesos de producción hasta la exportación. Para las empresas agrícolas que recién ingresan a la producción agrícola, hay barreras para obtener los factores de la producción, especialmente terrenos en gran escala y capitales.

En el Perú, la tenencia de terrenos agrícolas en gran escala por parte de las empresas fue restringida desde la época de la reforma agraria de 1969 hasta la década de 1980. Por tal motivo, en la producción de espárragos blancos para conservas, se desarrolló la estructura de abastecimiento, mediante la cual los medianos y pequeños agricultores producen el cultivo y abastecen de la materia prima a las plantas de procesamiento. Cuando se aplicó la liberalización de la economía en la década de 1990, se eliminó la restricción de la tenencia de terrenos agrícolas a gran escala.

Además, los terrenos de gran escala estaban disponibles gracias al proyecto de irrigación Chavimochic en el norte y al saneamiento de la propiedad de los terrenos en el sur. Con la nueva tecnología de irrigación los terrenos abandonados por la baja productividad fueron convertidos en terrenos altamente productivos.

Además de la liberalización de la propiedad de terrenos agrícolas de gran escala, la liberalización de la economía y su crecimiento estable facilitaron las inversiones del sector agrícola para la exportación. En el Cuadro N. ${ }^{\circ} 3$, se detallan las características

de las empresas agrícolas que exportan espárragos. Algunas empresas obtuvieron los capitales de otros sectores, tales como manufactura y minería. Otras empresas atrajeron inversionistas extranjeros.

En el Cuadro N..$^{\circ}$, se incluye a las empresas que exportan espárragos en conserva. Estas empresas primero compraban la materia prima de los medianos y pequeños agricultores. Recientemente, está aumentando la producción en fincas propias de gran escala y están disminuyendo su dependencia de los productores externos. Mientras tanto, las empresas que exportan espárragos frescos se han abastecido desde el principio de fincas propias. 


\section{El caso de los valles de La Libertad $\in$ Ica}

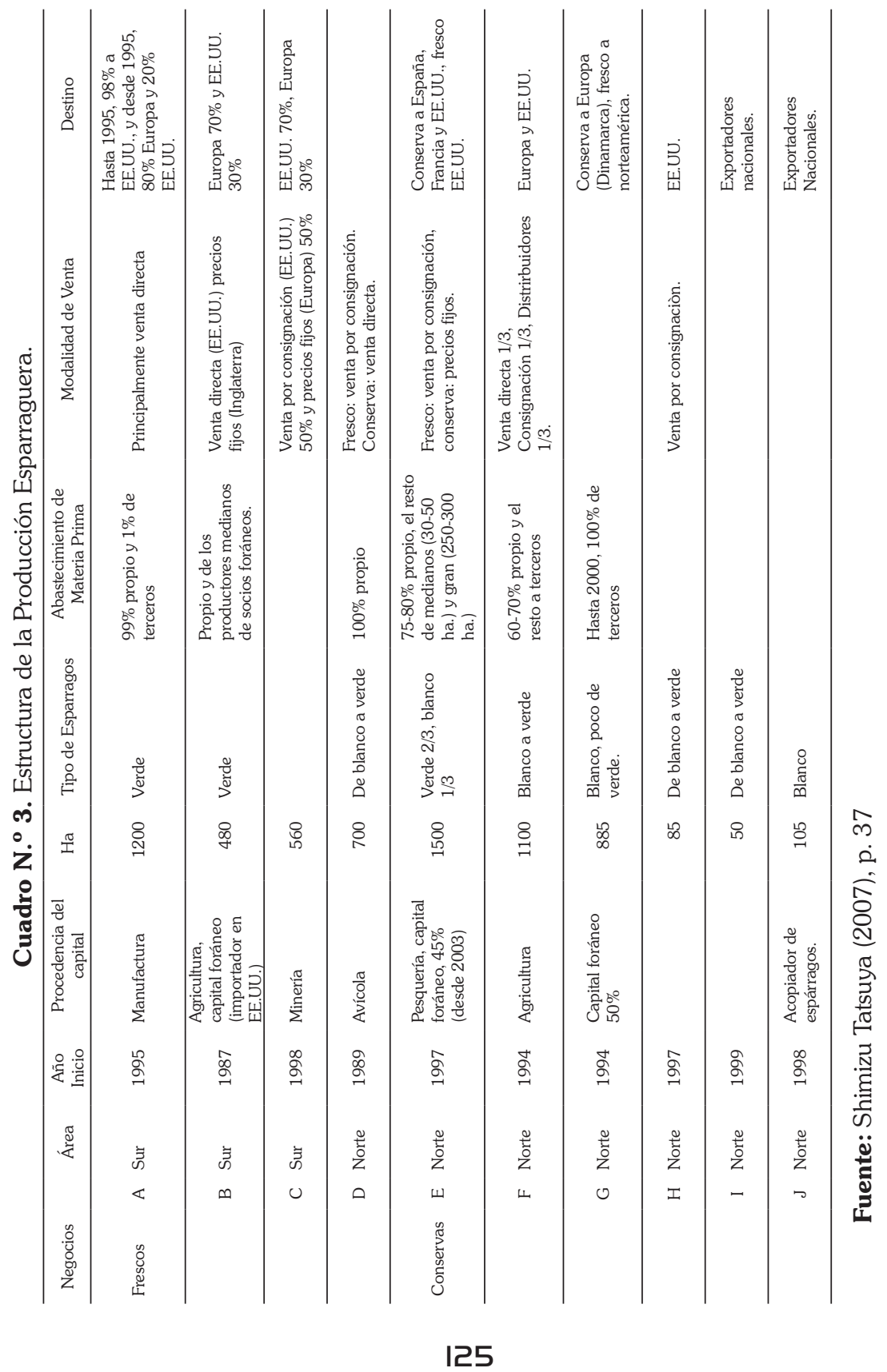




\section{Johans Julio E. V. López Mas / Pablo M. Condori Luna}

Existen también los procesos de integración productiva de los espárragos frescos y en conserva. El nodo final del procesamiento de los espárragos frescos es, en muchos casos, el importador (comisionista). Además, la tecnología en el proceso "construccion de bases logísticas" tiene requerimientos de capital que están lejos del alcance de los pequeños agricultores, lo cual implica la necesidad de asociarse.

De otra parte, se observa que para el caso de los espárragos en conserva se da la compra sin contrato de los acopiadores a los pequeños y medianos agricultores, situación que en algunos casos permanece hasta la actualidad. Lo cual representa que el agricultor asume mayores riesgos de los que asume el resto de los integrantes de la cadena productiva.

Es importante presentar las caracteristicas de dos empresas líderes del sector esparraguero:

- El Consorcio Agroindustrial Camposol situado en Chavimochic - La Libertad, es la principal industria agroindustrial del país. El 2007 realizó ventas por, aproximadamente, US\$130 millones, casi tres veces más que Drokasa del grupo Chlimper. Tiene 18 $000 \mathrm{Ha}$, de las cuales $6000 \mathrm{Ha}$ están bajo producción: 2945 Ha de espárrago, $981 \mathrm{Ha}$ de palta y 415 Ha de mangos (en Piura). Camposol es la principal productora nacional de esparragos blancos y verdes, frescos y congelados, envasados y salpimentados, y se proyecta como el primer productor de paltas del mundo. Contrata 10000 trabajadores (3500 en planta, y el resto en campo, logística y administración). Su importancia se infiere del dato que en toda la irrigacion de Chavimochic, la oferta laboral supera las 40000 personas. En noviembre de 2007, Camposol cambió de propietarios. Fundada en 1997 por el Grupo Gonzales, fue adquirida por un consorcio de empresas y fondos de inversion nacionales e internacionales liderados por el peruano Grupo Dyer (28\% de las acciones) en, aproximadamente, US\$ 180 millones.

- Agrokasa del Grupo Chlimper forma parte de los pioneros de este proceso de modernizacion de la agroexportación iniciada en la decada del noventa del siglo pasado. Cuenta con 1810 Ha en sus fundos de Ica (Santa Rita y La Catalina) y Las Mercedes en Barranca; y vende, aproximadamente, US\$ 50 millones, atendiendo a 30 paises. Se destaca por su grado de tecnificación y actualmente son importantes productores y exportadores de esparragos, uva de mesa y está incursionando en la palta. Jose Chlimper, en una entrevista concedida al diario Gestion (30.6.08), señaló 


\section{El caso de los valles de La Libertad e Ica}

que el objetivo empresarial de Agrokasa (parte de la Corporacion Drokasa S.A.) es diversificar la oferta exportable para balancear los riesgos a futuro. Además, tienen previsto comprar 1200 Ha en el norte del país para ampliar sus cultivos de espárragos y paltas. Sin embargo, por la actual crisis internacional, están en suspenso estos planes. El plan de inversiones 2008 fue de US\$ 8 millones, destinándose US\$ 3 millones a sus fundos de Ica y US\$ 5 millones a Las Mercedes, en Barranca. Esta inversión considera equipos nuevos de reingenieria de pozos, mejoramiento de los sistemas de riego y, principalmente, la instalación de una planta de fertilizantes liquidos dentro del fundo de Barranca (US\$ 1.6 millones). La diversificacion productiva es una de las estrategias más activas para enfrentar la crisis internacional actual. El Complejo Camposol considera esta diversificacion productiva como una de sus fortalezas. Aunque el precio del espárrago verde fresco bajó, el espárrago blanco sigue por encima del punto de equilibrio, mientras que la palta es aceptada en forma creciente en los mercados internacionales.

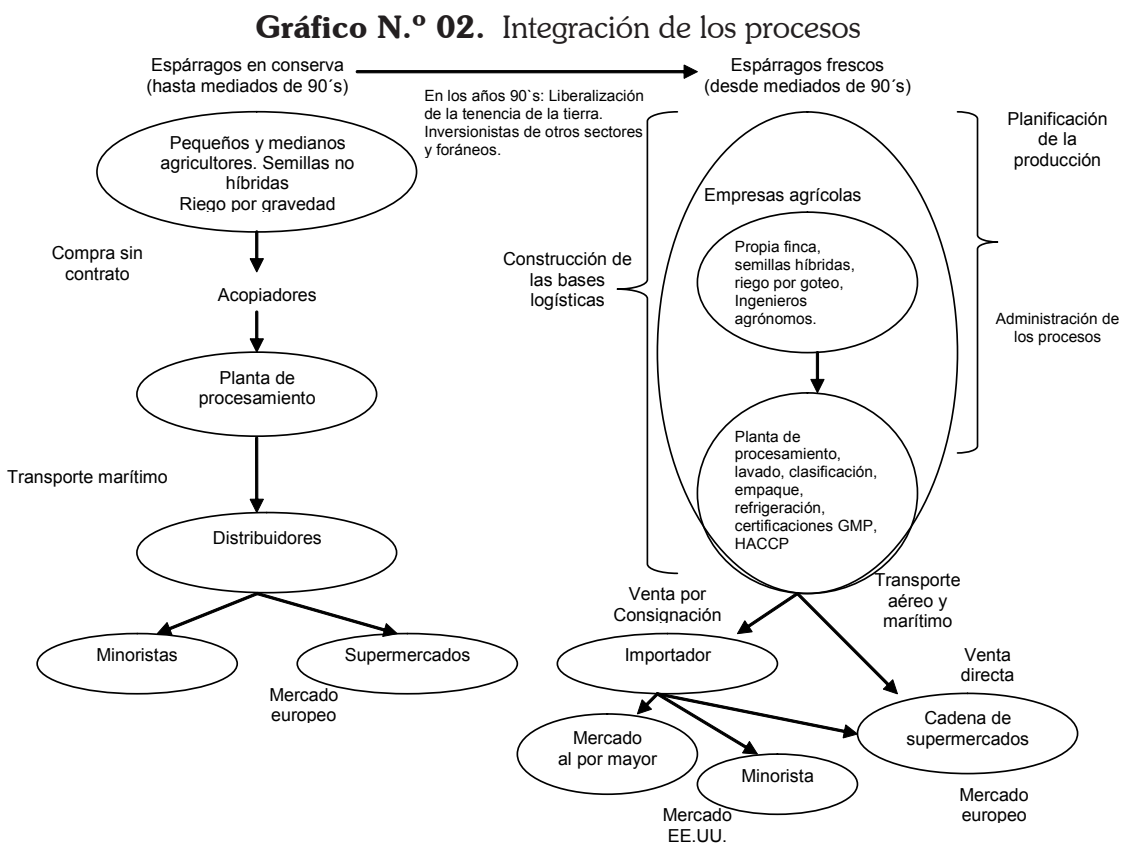

Fuente: Shimizu Tatsuya (2007); p. 38. 


\section{Johans Julio E. V. López Mas / Pablo M. Condori Luna}

En estas circunstancias, los directivos de Camposol, en una reciente entrevista concedida a la revista Caretas (18.12.08), indican con optimismo “... que el balance negativo en esparragos fue contrarrestado por las ganancias en la palta, y que la historia de las recesiones mundiales demuestra que el rubro de alimentos es el de menor impacto en las crisis economicas: simplemente porque la gente no deja de comer ..."

\section{CADENA LOGÍSTICA EN LA DISTRIBUCIÓN DEL ESPÁRRAGO}

En el 2003, el Programa de Apoyo a la Competitividad de la CAF buscó investigar un conglomerado productivo cuya cadena logística fuera un tema crítico en su desempeño. El objetivo general fue identificar ese sector, hacer un estudio del mismo y encontrar las acciones específicas que se puedan realizar para eliminar los principales obstáculos en su cadena logística. El objetivo final era mejorar la eficacia y eficiencia de dicho conglomerado. El estudio fue encargado a un equipo de la Universidad Politécnica de Valencia, España. En el Perú, el sector identificado fue el espárrago verde fresco para exportación.

La asociatividad que propone la CAF a través de este estudio, parte de la comprensión de la importancia de la cadena de frio, aunque esto sugiere una mayor concentración de la producción que involucre productores - acopiadores - exportadores. Es notable el énfasis que se pone en la escala de producción para la sostenibilidad del abastecimiento a los mercados internacionales. El cluster constituido por el IPEH y Frio Aéreo Asociacion Civil fue el resultado de este estudio.

Frio Aéreo canaliza el $80 \%$ de los espárragos frescos que se envían por vía aérea utilizando el terminal de la asociación, la cual brinda servicios a todos los exportadores de esparragos frescos las 24 horas del día y los 365 días del año a tarifas competitivas del mercado. La infraestructura de Frío Aéreo prácticamente se ha duplicado al 2008, con la ampliación del área de almacenaje, construcción de nuevas cámaras de refrigeración, así como áreas de servicios adicionales para mejorar la atención hacia los exportadores, las agencias de carga y las aerolíneas.

La capacidad de almacenaje supera las mil toneladas de producto. Frío Aéreo cuenta con un área total de instalaciones de $6710 \mathrm{~m}^{2}$; de los cuales, cerca de 3000 


\section{El caso de los valles de La Libertad e Ica}

$\mathrm{m}^{2}$ son destinados al almacenaje de productos en condiciones de refrigeración exclusivamente.

\section{ANÁLISIS Y DISCUSIÓN}

Se observa que existe un "piso" o límite físico en el uso de los recursos que no son mano de obra para la producción de espárragos. Por más intensivo que sea en capital, cada una de las empresas agroexportadoras tiene una escala de rendimientos decrecientes, lo cual les obliga a generar excedentes con la contribución de la mano de obra (sea directa en los centros de producción, o indirecta a través de los subcontratados). Por una parte, no se puede remplazar totalmente la participación total de la mano de obra por maquinarias y equipos; por otra parte, existe un límite en la frontera agrícola y, por lo tanto, en los rendimientos de la tierra cultivable. Este hecho implica que en un determinado momento, para que las zonas de producción esparragueras puedan competir ventajosamente con países (particularmente con China) tendrán que apelar a salarios más bajos (o en su defecto, acuerdos de subcontrata más beneficiosos).

Este límite potencial, obligará a una reducción de salarios, lo cual (ante un aumento de los requerimientos de calidad de vida de la población) generará una mayor precarización, así como la mantención de la agricultura de contrata. La precarización del sector laboral agrícola constituye un factor importante en la ventaja competitiva internacional de exportación de espárragos.

Se observa, además, una relación tensa entre pequeños productores agrarios, por una parte; y los acopiadores, industrias y exportadores, por otra. Se ha documentado en el texto de Valcárcel (2002) que los agricultores asumen dos tipos de riesgo (crediticio y tecnológico) y que frente a ello no reciben (en su mayoría) asistencia crediticia y/o técnica, lo cual sería importante para mantener sus niveles de ganancia. Por ello están expuestos con mayor vulnerabilidad, por ejemplo, a un aumento de las tasas de interés. Por otra parte, una inexistente política estatal de promoción de asistencia técnica que promueva el aumento de la productividad y/o un mayor rendimiento por hectárea hace que los agricultores sean más vulnerables a la variación de precios y/o a la mayor demanda de tierra cultivable. 


\section{Johans Julio E. V. López Mas / Pablo M. Condori Luna}

El poder de negociación del agricultor frente al acopiador, es débil. El acopiador, además de utilizar el precio como un instrumento de negociación que desplaza el riesgo del valor del producto al agricultor, utiliza la calidad del producto como otro elemento de negociación. Al solicitar cada vez más requerimientos de calidad (producto de la demanda internacional) y no verse compensado en su integridad ni por un aumento de la productividad (que aminore el costo unitario) o un aumento del precio, en el corto plazo se afecta el precio que obtiene el agricultor.

Al carecer de asistencia técnica y/o crediticia para asumir posibles riesgos en la producción, la mediana empresa requiere de una articulacion con la pequeña producción agrícola, para que esta asuma tales riesgos y sea flexible ante las variaciones de los precios internacionales. La escala y el poder de negociación impiden que en el mediano (y largo plazo) el agricultor logre mejoras en el ciclo de acumulación, inversión y mejora de la productividad. Por el contrario, en el contexto actual, es posible que la gran empresa prefiera un conjunto disperso y excluido de producción subordinada y no una red de agricultores asociados.

El autor Tealdo (2002) señala que la migración no afecta mayoritariamente la productividad en la producción del espárrago, y coincidimos con ello; dado que existe en algunas zonas del Perú, un exceso de mano de obra en busca de oportunidades de empleo y dispuesta a migrar. Quizá uno de los principales problemas es que la producción de espárragos ha llegado o está muy cerca del punto caracterizado por rendimientos decrecientes en el uso del factor trabajo y que, por el contrario, los aumentos en la productividad deben obtenerse mediante inversiones en otros factores como la infraestructura (vial, de comunicaciones y de riego), en la ampliación de la frontera agrícola, la cadena logística y de frío, o la innovación tecnológica.

Existe, además, en el mercado de trabajo un excedente estacional "activo", caracterizado por buscar empleo, incluso en periodos fuera de cosecha, y otro "pasivo" que espera a la siguente campaña; pero ambos se constituyen en formas extrañas y temporales de provisión de ciertos servicios sociales (por ejemplo: cuidado de la seguridad ciudadana, vigilantes) o a actividades económicas (por ejemplo: el comercio ambulatorio), que al no ser absorbidos por el mercado local, devienen en una baja de los salarios y de las demás condiciones de vida de las regiones en donde se manifiesta. Así, los mi- 


\section{El caso de los valles de La Libertad $\in$ Ica}

grantes que viajan desde la periferia de las zonas de producción (Cajamarca, Amazonas y San Martín, en el caso de la Libertad; Ayacucho y Huancavelica, en el caso de Ica), presionan hacia la baja de salarios y se convierten en residentes locales precarios, sobre todo en épocas fuera de campaña; presionando hacia una mayor demanda de servicios públicos particularmente sociales.

El mercado de trabajo es particularmente sensible a las fluctuaciones de la demanda; en particular, debido al desplazamiento de trabajo permanente, por el trabajo eventual, y que en las condiciones actuales, carece de formas de protección y/o seguridad social adecuadas, aumentando su vulnerabilidad. Esto sucede pese a que existe una normatividad que regula el mercado de trabajo en el caso agrícola de exportación. Se requiere mayor regulación e inspecciones laborales que acerquen las prácticas empresariales a los requerimientos mínimos de bienestar de los trabajadores.

\section{CONCLUSIONES}

De la investigación descrita, se han obtenido las siguientes conclusiones:

a) Los factores que explican una precarización del empleo y asimetrías en la distribución de los ingresos en las zonas agrícolas esparragueras de exportación, pese a diferencias de orden tecnológico y de productividad, se refieren principalmente a las características de las grandes empresas, los importadores y los acopiadores; así como la dinámica del mercado internacional de este producto.

b) Encontramos de manera general una precarización del empleo agrícola y agroindustrial, el cual se basa, el primero, en una gran abundancia de mano de obra migrante de las áreas de influencia aledañas y que se caracterizan por tener niveles de pobreza extrema, los cuales presionan hacia una baja de los salarios; y en el caso del empleo agroindustrial, pese a que tienen mejores ingresos y condiciones de estabilidad, sin embargo, su poder de negociación con los empleadores y demás miembros de la cadena es reducido, encontrándose, por otro lado, pocos esfuerzos del Estado en la regulación de las condiciones de vida de las poblaciones. Un caso similar ocurre con la relación entre la producción de agricultura de subcontrata, que sirve como oferta permanente tanto de capacidad de producción como de insumos y mano de obra. Esta agricultura de subcontrata asume también los ries- 


\section{Johans Julio E. V. López Mas / Pablo M. Condori Luna}

gos de mantener esta capacidad de producción a disposición del acopiador y/o exportador.

c) Las tendencias actuales del mercado internacional hacen que este producto tenga algunas dificultades para su prosperidad y sostenibilidad en el mediano plazo, la razón fundamental de esto es que los países con los que el Perú compite a nivel internacional, pese a las ventajas naturales (áreas extensas, tecnología), cuentan con una importante dotación de mano de obra de bajo costo, lo cual presiona hacia la baja a los precios internacionales, toda vez que la contribución del trabajo manual es aún importante en el proceso productivo.

d) Ante la existencia de esta situación de crecimiento polarizado (en que el productor asume más riesgos que el comercializador) una alternativa posible sería la presencia estatal en la prestación de asistencia técnica y/o crediticia, con el propósito de incrementar la presencia de la pequeña producción modernizada y que pueda incorporarse a la cadena mundial de exportación esparraguera. La existencia de una red de agricultores organizados y asociados podría ser una alternativa de desarrollo de dichas zonas empobrecidas y que actualmente, tienen un beneficio sesgado hacia la gran empresa, la que aprovecha de la asociatividad público-privada.

\section{BIBLIOGRAFÍA}

Caro, Carlos. "La articulación de la agroindustria y la pequeña agricultura de los valles de Chao y Virú". En: Hurtado, Isabel; Trivelli, Carolina; Brack, Antonio (Editores). Seminario permanente de Investigación Agraria. SEPIA - Institut de recherche pour le développement. IRD - Intermediate technology development group. ITDG. Lima, 2000.

Fernandez-Maldonado, Enrique. "La Agroexportación en el país de las maravillas". En: Revista Quehacer. DESCO. N. ${ }^{\circ}$ 163, Lima, noviembre y diciembre, 2006.

Huerta Fernández, Alfonso Pablo. "Efecto de diferentes niveles de fertilización en el incremento de productividad de espárrago en el valle de Virú". Lima, Asamblea Nacional de Rectores - ANR, 2006.

Marañón, Boris. "Obreros en la industria esparrarraguera: valles de Chao - Virú e Ica. En: DEBATE AGRARIO: Análisis y alternativas. N. ${ }^{\circ}$ 17, Lima, Centro Peruano de Estudios Sociales - CEPES, diciembre de 1993, Director: Fernando Eguren; pp. 27-52. 


\section{El caso de los valles de La Libertad $\in$ Ica}

Minaya, José Elías. "Los Campesinos y la agroindustria del espárrago en el valle de Virú". Trujillo, Instituto de Investigaciones Sociales. Facultad de Ciencias Sociales, Universidad Nacional de Trujillo, 1995.

Montoya, Maibi. Asociados para liderar. El cluster de espárragos del Perú. Corporación Andina de Fomento (CAF). Colección PAC, Clusters II, 2003.

Ministerio de Agricultura (MINAG). "Primer censo nacional de productores de espárrago 1998". 1. ${ }^{\text {er }}$ Censo Nacional de Plantas Procesadoras de Espárragos 1998. Perú.

Shimizu Tatsuya. "El cambio de la estructura de la exportación de espárragos peruanos". Presentado en el Tema III: "Agricultura Comercial Moderna", para SEPIA XII, en Tarapoto, 13 - 16 de agosto de 2007.

Tealdo, Armando. "Mercado de trabajo y empleo en el sector agrario". En: DEBATE AGRARIO: Análisis y alternativas. N. ${ }^{\circ} 34$, Lima, julio de 2002, Centro Peruano de Estudios Sociales - CEPES, Director: Fernando Eguren; pp. 1-27.

Valcárcel Carnero, Marcel. "Nuevas relaciones sociales entre los productores, la industria agroexportadora y las ONG en el sector agrario peruano". Estudios del sistema de producción de los espárragos entre 1980 y 2000. Presses Universitaires de Louvain, Bélgica, 2003, 329 pp.

Valcárcel Carnero, Marcel. "Agroexportación no tradicional, sistema esparraguero, agricultura de contrata y ONG". En: Análisis y alternativas. N. ${ }^{\circ} 34$, Lima, julio de 2002, Centro Peruano de Estudios Sociales - CEPES, Director: Fernando Eguren, pp. 29-44.

\section{Páginas Web:}

Ministerio de Agricultura - MINAG. www.minag.gob.pe

III Censo Nacional Agropecuario 1994. www.portalagrario.gob.pe/censo/censo1.shtml

Dirección Regional de Agricultura de Ica. www.agroica.gob.pe/tematica.shtml Insituto Peruano del Espárrago. www.ipeh.org

ONU. Food and Agriculture Organization (FAO) www.fao.org/index_es.htm

PERÚ. Comisión para la promoción de la exportación y el turismo PROMPERU. www. promperu.gob.pe 